\title{
Emotional Intelligence, Emotional Labour and Organisational Citizenship Behaviour in service environments
}

\author{
Yashotha Ramachandran, Peter J. Jordan*, \\ Ashlea C. Troth and Sandra A. Lawrence
}

Griffith Business School,

Griffith University,

Nathan Q 4111, Australia

Fax: (+61) 737353887

E-mail: yrama83@gmail.com

E-mail: Peter.Jordan@griffith.edu.au

E-mail: A.Troth@griffith.edu.au

E-mail: S.Lawrence@griffith.edu.au

${ }^{*}$ Corresponding author

\begin{abstract}
There is increasing recognition regarding the role of emotions in predicting the performance of workers. In particular, there has been extensive interest regarding the constructs of Emotional Intelligence and Emotional Labour in the promotion of more productive worker behaviour. Research focusing on emotions in the workplace has typically been conducted within western settings. In this study, we examine the impact of Emotional Intelligence (EI) on Emotional Labour (EL) and Organisational Citizenship Behaviour (OCB) in the Malaysian service industry. Data were collected from 131 front desk employees across four resorts within a Malaysian hotel chain. In line with expectations, analyses revealed that EL partially mediated the relationship between EI and OCB. Implications for theory and practice in non-western settings are discussed.
\end{abstract}

Keywords: EI; emotional intelligence; EL; emotional labour; OCB; organisational citizenship behaviour; service industry.

Reference to this paper should be made as follows: Ramachandran, Y., Jordan, P.J., Troth, A.C. and Lawrence, S.A. (2011) 'Emotional Intelligence, Emotional Labour and Organisational Citizenship Behaviour in service environments', Int. J. Work Organisation and Emotion, Vol.

Biographical notes: Yashotha Ramachandran is an Account Executive based in Malaysia. She completed her Bachelor of Commerce (Honours Class 1) at the Griffith Business School, Griffith University, Australia. Her research interests are in the areas of emotional intelligence, emotional labour and international HRM.

Peter J. Jordan is a Professor of Organisational Behaviour in the Griffith Business School, Griffith University, Australia. He gained his $\mathrm{PhD}$ in management at the University of Queensland. His current research interests include emotional intelligence, emotions in organisations, team performance and leadership. 
Ashlea C. Troth is a Senior Lecturer in the Griffith Business School, Griffith University, Australia. She gained her $\mathrm{PhD}$ in psychology at the University of Queensland. Her current research interests include communication, emotional intelligence, and employee adjustment during organisational change.

\begin{abstract}
Sandra A. Lawrence is a Research Fellow in the Centre for Work Organisation and Well being in the Griffith Business School, Griffith University. She gained her PhD in management at the University of Queensland. Her current research interests are in emotional regulation during organisational change, team interpersonal dynamics and performance, workplace social support, stress and coping, and workplace productivity.
\end{abstract}

\title{
1 Introduction
}

Service employees who are able to manage their emotions effectively enhance their organisation's performance and image, and promote customer satisfaction and loyalty (Härtel et al., 2008; Grandey et al., 2005). Studies examining how emotions are displayed and experienced in the service industry have emphasised the concepts of Emotional Intelligence (EI) (Mayer and Salovey, 1997) and Emotional Labour (EL) (Hochschild, 1983). EI refers to abilities that assist in the recognition and management of emotive information (Mayer and Salovey, 1997), while EL concerns the display of appropriate emotions to enhance one's job performance (Hochschild, 1983). EL has two basic components, surface acting (displaying emotions that are not felt through staging of verbal and nonverbal cues) or deep acting (experiencing or feeling the emotions that are required) (Brotheridge and Grandey, 2002). Also of research interest in the service industry has been the role of Organisational Citizenship Behaviour (OCB), voluntary behaviours that are not part of an employee's formal job duties that enhance organisational performance (Organ, 1988). OCB is related to outcomes such as superior service quality (Yoon and Suh, 2003), customer satisfaction and customers' future behavioural intentions (Castro et al., 2004). Interest of the impact of OCB on work behaviours has now become widespread with cross cultural research being published in relation to a number of countries (Han and Altman, 2010; Lam et al., 1999).

The aim of our study is to present and test a conceptual framework proposing that EL abilities mediate the link between EI and OCB within a hotel service setting. Understanding the relationships between these variables will enable managers to generate positive workplace behaviours that can contribute to better service interactions (Grandey, 2003). By examining this relationship in a non-Western context (i.e., Malaysia), we hope to examine the generalisability of workplace emotion constructs and processes beyond Western organisational contexts (Fisher and Ashkanasy, 2000). To date, such research is limited (see Grandey et al., 2005).

\section{Emotions in service jobs}

The experience and display of emotions in service settings is important. Customers who receive good service from service providers are likely to spend more time using the service, be more willing to return, and recommend the service to others (Tsai and Huang, 
2002). Studies performed on a range of service industry samples, from school teachers (Meier et al., 2006) to restaurant employees (Hallett, 2003), have found that service employees are required to manage their own emotions in order to manage the emotions of customers (Leidner, 1999).

Ashforth and Humphrey (1993) argue that the management of emotions is relevant for workers in the service industry and that assessments of service quality are often predicated on emotion. A customer's interaction with a service employee plays a role in defining their judgement of service quality (Galli and Zammuner, 2005) and is the main determinant of customer loyalty and satisfaction (Hennig-Thurau et al., 2006). Within the hotel industry, we argue that employees will be more successful in their dealings with customers if they utilise OCBs (e.g., extra effort, showing initiative, customer orientation). In order to generate OCBs, an appropriate affective state needs to be created. This is enabled by higher levels of genuine positive emotion displays (EL) activated via the mechanism of deep acting. We provide no predictions related to surface acting as these are organisationally prescribed and as such do not require significant emotional skills (e.g., following instructions to smile when greeting customers). Finally, we contend that deep acting is enabled by EI abilities. Thus, greater EI abilities enhance an employee's ability to deep act and, in turn, these positive emotions promote OCB. Organisational, collegial relationships and improved customer-service experiences will be promoted as a result of this process. To date, research shows a link between EI and $\mathrm{OCB}$ on the basis that EI abilities enable employees to engage with the organisation (Côté and Miners, 2006). In this paper, we examine this relationship and argue that greater EI abilities enhance an employee's ability to deep act, and that emotional labour contributes to the positive emotions required to promote OCB (see Figure 1).

Figure 1 A model of emotional intelligence emotional labour and organisational citizenship behaviours in a service environment

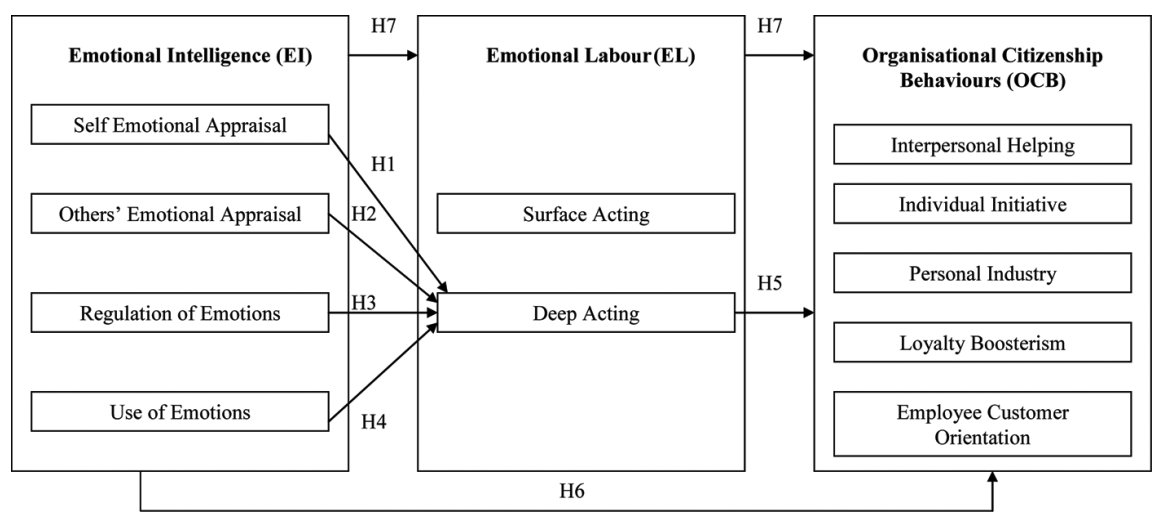

\section{Emotional intelligence and service jobs}

Mayer and Salovey (1997) argue that EI consists of four interconnected abilities involved in the processing of affective information:

- perceiving emotions

- using emotions to facilitate thinking 
- understanding emotions

- regulating the emotions of others and one's own emotions.

A significant debate has emerged over the construct of EI with questions being asked about both the construct definition and its measurement. Daus and Ashkanasy (2005) note that there are two broad streams of EI research. The first derives from the ability model of EI and is firmly steeped in intelligence research. The ability model of EI clearly links emotion to cognition and as a result seeks to measure EI using ability (task performance) measures. This is the model based on the work of Mayer and Salovey (1997). The second stream of EI research is based on a trait approach to EI. This model combines variables that encompass specific aspects of personality and then link these to emotional constructs (Petrides et al., 2007). The trait model of EI incorporates factors of personality into an overall construct which includes variables such as empathy (Goleman, 1998) and well-being (Bar-On et al., 2006). In recent work, Cherniss (2010) and Jordan et al. (2010) note the importance of context in assessing EI and suggest that specific work-based measures of EI are important for making the link between EI and work behaviours. Drawing on the Mayer and Salovey (1997) tradition of examining EI as the link between emotion and cognition, and looking at the work context, Wong and Law (2002) conceptualised EI as containing four distinct dimensions: Self Emotional Appraisal (SEA), Others' Emotional Appraisal (OEA), Regulation of Emotion (ROE), and Use of Emotion (UOE).

Self Emotional Appraisal concerns an individual's capacity to understand their emotions and to be able to exhibit these emotions. Due to the high amount of interaction with customers in service jobs (Daus and Ashkanasy, 2005), it is imperative that service employees are aware of their own emotions before being able to deal with customers. OEA relates to an individual's ability to identify and understand the emotions of people around them. Lopes et al. (2005) believe the ability to perceive and understand emotion has a direct influence on social interactions, as it helps individuals interpret internal and social cues. This guides emotional self-regulation and social behaviours, particularly important skills in service settings (Lopes et al., 2005). ROE is an individual's ability to manage his or her emotions. Côté and Miners (2006) argue that the regulation of emotions influences the quality of social relationships, and in service jobs this can affect task performance when dealing with customers. Finally, UOE refers to the ability of individuals to utilise their emotions by aligning emotions with productive activities. Many service organisations have expectations about which emotions should be displayed by employees to customers (Giardini and Frese, 2006). Therefore, it is important for service employees to effectively generate emotions to create a positive service environment that contributes to customer satisfaction and future loyalty (Hennig-Thurau et al., 2006).

\section{Organisational citizenship behaviour and service jobs}

Another set of behaviours that are considered to enhance service exchanges are OCBs. OCBs refer to individual contributions within the organisation that exceed specified role requirements. They are not recognised by the formal reward system, either directly or indirectly (Organ, 1988). OCBs include interpersonal helping (helping co-workers); individual initiative (expressing opinions to increase group and individual functioning); 
personal industry (working with care, meeting deadlines, and low absenteeism); and loyalty boosterism (promoting the organisation's image) (Moorman and Blakely, 1995). This taxonomy is aligned with Organ's (1988) conceptualisation of OCB. Each of these OCB dimensions contributes to a positive service environment. Helping co-workers can result in a better service environment in which the pressure of meeting customer expectations will be shared across a service team. Individual initiative and personal industry can result in reduced errors, errors being addressed before they arise, or early in the process. Finally, Loyalty Boosterism promotes the brand of the organisation by talking confidently about the organisation and will result in a more positive service encounter with customers taking away an optimistic impression from each service encounter.

OCBs that impact on the customer-service experience are particularly suited to the present research context of hotel counter staff. Albrecht and Zemke (1985) suggest that central to service organisations, is the need to concentrate on customers' wants, needs and expectations. Therefore, having well-trained, customer service oriented employees is vital to such organisations. In line with the standard set of OCBs suggested by Moorman and Blakely (1995), we also include customer service orientation (i.e., active engagement in servicing customers' needs) as an additional measure of OCB (Johnson, 1996), as this reflects the extra effort and personal initiative typifying OCB.

\section{Emotional intelligence and organisational citizenship behaviour in service jobs}

Research has demonstrated that EI is related to OCB (Wong and Law, 2002). EI promotes empathic behaviour by allowing employees to understand others' feelings and thus respond to others better. Such behaviours are important in service settings where employees work in teams to meet customer needs. By being aware of their own emotions and the emotions others are experiencing, employees are able to recognise when their fellow employees require assistance and when they need to be more actively engaged in addressing their customers' needs. This also applies for those wish to develop a strong customer orientation. Employees with high EI understand that a strong customer orientation can be facilitated by emotional interactions. By managing their own emotional displays and experiences to display positive emotions in the workplace, high EI employees are more likely to engage in helpful behaviours and extra role activities that result in better customer service (Abraham, 2003). Based on these arguments we expect that:

Hypothesis 1: EI will be positively linked to OCB.

If OCB can produce a better service encounter, then organisational performance would be enhanced by determining variables that facilitate the relationship between EI and OCB. In this paper we argue that emotional labour, in particular deep acting, will mediate this relationship.

\section{Emotional labour and service jobs}

The concept of EL (Hochschild, 1983) refers to the management of one's feelings and emotional displays for a wage. An essential principle is that employees are expected to 
follow organisational display rules that identify which emotions are appropriate and how these emotions should be displayed to others (Diefendorff and Richard, 2003). Employees engaged in jobs with greater interpersonal demands (Wharton, 1993), such as hotel front desk staff, need to expend effort and self-control to communicate organisationally desired emotions (e.g., cheerfulness and friendliness) during service encounters (Hochschild, 1983). In order to conform to these display rules, employees often engage in one of two common methods of acting, surface acting or deep acting (Brotheridge and Grandey, 2002). Both of these forms of acting are used by employees to align their displayed emotions with organisational display rules/norms. We contend that, although most employees are able to follow organisational rules and surface act (e.g., to smile when greeting a customer), deep acting (e.g., to actually be happy) requires greater emotional abilities. Totterdell and Holmann (2003) conducted a study using call centre staff and found that deep acting was related to service performance whereas surface acting was not.

\section{Emotional intelligence and emotional labour in service jobs}

Previous research shows a link between trait EI and both surface acting and deep acting (Mikolajczak et al., 2007). This study, however, used a unidimensional measure of trait EI and reported that the measure of EL did not distinguish between deep acting and surface acting. Figure 1 proposes a number of links between the dimensions of EI and EL. First, SEA represents the most fundamental aspect of EI, making all other information processing possible (Salovey and Grewal, 2005). To surface act, employees do not require SEA ability as they need merely to follow organisationally prescribed rules. To enable deep acting, however, employees need to identify their own emotional state before being able to deal with their customers (Johnson and Indvik, 1999) and emotional self awareness facilitates this. A number of studies outline the importance of self awareness in interpersonal communication (Daus and Ashkanasy, 2005). To enable deep acting and good communication, an essential component of good customer service, service providers require awareness of their own emotional state to determine if that state needs to change. On this basis, we predict that:

Hypothesis 2: The ability to undertake self-emotional appraisal (SEA) is positively related to deep acting.

The ability to recognise others' emotions is critical in a service environment. In this context, display rules are prescribed to ensure a consistent response (Diefendorff et al., 2006). Consequently, specific surface acting is mandated by the organisation in all situations. For instance, even when dealing with an angry client, employees will be instructed to be pleasant and polite. On the other hand, deep acting requires a decision to engage emotions (Brotheridge and Grandey, 2002). After observing a customer's emotions and feelings, deep acting requires employees to understand those emotions and determine the most appropriate genuine emotions for an interaction (Abraham, 2003). For instance, in dealing with a difficult customer it is important to be aware of a customer's anger and show empathy for their situation rather than deal with the situation with a simple smile (surface acting). Therefore, we predict:

Hypothesis 3: The ability to appraise others' emotional states (OEA) will be positively related to deep acting. 
In order to change emotional displays and behaviour in social interactions we need to manage our emotions (Lopes et al., 2005). In surface acting, emotional displays are altered to match organisational display rules and no specific emotional regulation is required. For deep acting, however, emotions need to be regulated by controlling internal thoughts and feelings to align with display rules (Brotheridge and Grandey, 2002). A central tenet of deep acting is that emotions may need to be changed to match the organisation's display rules or to attain a genuine emotional state required to achieve organisational goals (Grandey et al., 2005). By deep acting, employees avoid emotional dissonance and provide a genuine emotional exchange with customers. Employees who have the ability to regulate their emotions will be more proficient at changing their emotional state to deep act. Therefore, we predict that:

Hypothesis 4: The ability to regulate emotions (ROE) will be positively related to deep acting.

Finally, employees need to effectively determine the appropriate emotions to produce positive responses from customers in order to foster good working relationships with them (Leidner, 1999). To enable a successful service encounter, workers need to generate emotions to manage customers' expectations of the service encounter. Within the EI literature this has been referred to as 'using' emotions. Employees with high EI are more effective at deep acting because they have the ability to process emotional information more accurately (Mayer and Salovey, 1997) and adjust their response to the emotional demands of the service situation (Giardini and Frese, 2006). If employees are going to use emotions effectively they need to be able to genuinely engage those emotions. Research has shown that customers are able to distinguish between genuine and forced emotion (surface acting) and will be more responsive to genuine emotion. Thus:

Hypothesis 5: The ability to use emotions to achieve a desired emotional state (UOE) will be positively related to deep acting.

\section{Emotional labour and organisational citizenship behaviour in service jobs}

Diefendorff et al. (2006) conducted a study investigating the relationship between EL and OCB and concluded that employees who genuinely display more positive behaviours (deep acting) in the workplace are more likely to engage in OCB compared to employees who fake and suppress their emotions (surface acting). Deep acting requires an employee to change his or her emotional state to comply with a customer's needs (Giardini and Frese, 2006) and this may produce a positive emotional climate that encourages interpersonal helping, generates individual initiative, and promotes positive customer orientation. The positive emotions generated by deep acting may also produce positive emotional contagion (Kelly and Barsade, 2001) which is linked to loyalty boosterism (Becker and Keman, 2003) and the extra role behaviours generated through personal industry (Frese and Fay, 2001). No relationship is predicted between surface acting and OCB as surface acting is a compliance behaviour that does not invoke the genuine emotional feelings thought to promote OCB. Based on these arguments, we predict that:

Hypothesis 6: Deep acting will be positively linked to OCB. 


\section{The mediating role of emotional labour}

Generally, EL is tested as an independent variable predicting outcomes (e.g., Rupp and Spencer, 2006) or as a dependant variable (e.g., Grandey, 2003). In our study, we argue that EL is a mediating variable. According to Baron and Kenny (1986), several conditions are required before mediation can be established. EI should be linked to OCB (Hypothesis 1). EI should be significantly linked to EL (Hypotheses 2-5). EL also should be significantly linked to OCB (Hypothesis 6). If all of these conditions are met, mediation can be examined by investigating the impact of EI on OCB while controlling for EL. We contend that EL will mediate the EI-OCB relationship. Specifically, we argue that the genuine emotion generated during deep acting will lead to greater OCB. We propose no relationship exists between OCB and surface acting. Surface acting involves a display of emotions that are not genuinely felt and are unlikely to trigger extra role behaviour. Based on this evidence we propose that:

\section{Hypothesis 7: Deep acting will mediate the effect of EI on OCB.}

Although there has been some research examining the relationships between EI and EL; EI and OCB (Wong and Law, 2002); and EL and OCB (Diefendorff et al., 2006), no research we are aware of has examined these constructs together within a single theoretical framework. Our study contributes to the field by providing a conceptual framework to consider how a validated measure of EI impacts on OCB and whether this relationship is mediated by the EL process of deep acting.

\section{Method}

\subsection{The context: the Malaysian service sector}

Research in the area of emotions predominantly involves Western organisational settings (Fisher and Ashkanasy, 2000). Yet many researchers believe the role of emotions should be investigated in non-Western contexts, and across various cultures, to explore differences or consistencies among emotional constructs and processes (e.g., Côté and Miners, 2006). We examine the relationships shown in Figure 1 with data collected from a Malaysian hotel service setting. The Malaysian service sector is the largest sector in the nation's economy (Tourism Malaysia Media Centre, 2007) and understanding how EI and EL combine to promote OCB is not only particularly relevant in this context, but findings from this study will inform whether the constructs and processes of interest can be generalised to non-Western settings.

The literature examining EI, EL and OCB in a Malaysian context is currently limited. While Wong and Law (2002) studied the impact of EI on managers and supervisors in China, there have been few EI studies conducted in Malaysian businesses. Some research into EI has used Malaysian samples to examine managerial effectiveness (Shipper et al., 2003) and career commitment (Poon, 2004). The Shipper et al. (2003) study, however, did not measure EI 'per se' but rather de facto measures of interactive skills and controlling skills. Poon's (2004) study utilised a measure of emotional perception only.

Our study extends this research by examining our mediated theoretical framework within a service context in Malaysia. We argue that the hypotheses, developed from 
Western theory and findings, should empirically apply and generalise to our non-Western context. While there has been research to show that emotional displays are similar across cultures (Ekman and Friesen, 1971), there is a debate regarding the difference between cultures in terms of the operationalisation of emotion in the workplace (Matsumoto, 1990). We believe in a Malaysian service sector setting, employees' EL and OCBs are particularly salient as such behaviours enable employees to meet their cultural and organisational obligations.

\subsection{Participants}

The sampling frame comprised 152 front desk employees from 4 resorts within a 5-star hotel chain in Malaysia. In total, 131 employees completed usable surveys (response rate $86.2 \%)$. Eighty-six $(65.6 \%)$ were male, the average age category of participants was 26-30 years of age, the majority of participants were of Malay ethnicity (76.3\%), with the remaining participants being Chinese $(12.2 \%)$ or Indian $(3.8 \%)$. The majority of participants had completed secondary school $(67 ; 51.1 \%)$, while $58(44.3 \%)$ had a certificate, diploma or apprenticeship. All participants were permanent full-time employees (average tenure 2 years, 9 months). All participants were in jobs where they had to interact with the resort's guests and engage in some form of EL.

\subsection{Procedure}

With the consent of management, the researcher approached front desk employees at the beginning of their shift. Participants were briefed about the nature of the survey, handed a copy to fill in, and were asked to leave the surveys, either complete or incomplete, at a single designated, secure location within the resort for collection by the researcher. A condition of employment in this 5 star hotel chain is that front desk employees are able to speak and understand written English and therefore all surveys were administered in English. Surveys were piloted for the wording of the questions and no problems were found with the survey. The researcher remained in the location for the duration of the study to clarify any translation issues.

\subsection{Measures}

Organisational citizenship behaviours (OCB): Moorman and Blakely's (1995) 19-item OCB Scale was employed to measure Interpersonal Helping (5 items; e.g., "I frequently adjust my work schedule to accommodate other employees' requests for time off"), Individual Initiative (5 items; e.g., "For issues that may have serious consequences, I express my opinions honestly even when others may disagree"), Personal Industry (4 items: e.g., "I rarely miss work even when I have a legitimate reason for doing so"), and Loyalty Boosterism (5 items: e.g., "I actively promote the organisation's products and services to potential users"). A 7-point Likert scale $(1=$ strongly disagree, $7=$ strongly agree) was used for scale anchoring. Alpha reliability coefficients reported for these OCB subscales have ranged from .61 to 86 (e.g., Moorman and Blakely, 1995). Johnson's (1996) employee customer orientation measure was adapted to measure employee customer Orientation in a hotel service setting. The 4-item scale required employees to rate their agreement with each statement (e.g., "I feel personally responsible for the work I do for my customers"), using a 5-point Likert scale 
( $1=$ strongly disagree, $5=$ strongly agree). Johnson (1996) reported an alpha reliability coefficient of $\alpha=0.83$ for this measure.

Emotional labour: Three items from the Emotional Labour scale (Brotheridge and Lee, 2003) were used to measure Surface Acting (3 items; e.g., "I pretend to have emotions that I do not really have") and Deep Acting (3 items; e.g., "I make an effort to actually feel the emotions that I need to display to others") on a 5-point scale $(1=$ never, $5=$ always). Reliability coefficients calculated by Brotheridge and colleagues (Brotheridge and Grandey, 2002; Brotheridge and Lee, 2003) for surface acting range from $\alpha=0.74$ to $\alpha=0.85$, and for deep acting range from $\alpha=0.82$ to $\alpha=0.83$. As indicated earlier, we do not expect significant relationships to be found between the EL process of surface acting and either EI or OCBs. Whilst it would be inappropriate to propose null hypotheses in relation to surface acting, we collected these data to ensure we had a comprehensive measure of EL.

Emotional intelligence: EI was assessed using Wong and Law's 16-item Emotional Intelligence Scale (WLEIS) (Wong and Law, 2002). Four subscales measured Self Emotion Appraisal (4 items: e.g., "I have a good sense of why I have certain feelings most of the time"), Others' Emotion Appraisal (4 items: e.g., "I have a good understanding of the emotions of people around me"), Regulation of Emotion (4 items: e.g., "I am able to control my temper so that I can handle difficulties rationally"), and Use of Emotion (4 items: e.g., "I always set goals for myself and then try my best to achieve them"). A 7-point Likert response format $(1=$ strongly disagree, $7=$ strongly agree $)$ was used. Reliability coefficients have been reported to range from 0.80 to 0.90 for each of these EI measures (Wong and Law, 2002).

Controls: Empirical research has found links between both demographic variables (e.g., sex, ethnicity and highest education level) and negative affect, EL (e.g., Gosserand and Diefendorff, 2005) and OCB (e.g., Messer and White, 2006). Demographic information (e.g., Sex, Ethnicity, and Education) and employees' Negative Affect were collected to enable control of these variables in the mediation analyses. Negative Affect was measured using the Positive and Negative Affect Scale (PANAS) (Watson, et al., 1988). Employees were asked to rate the extent to which they generally felt 10 negative emotional states (e.g., 'scared', 'irritable', 'distressed'), on a 5-point Likert scale $(1=$ never, $5=$ very often $)$. This measure is a reliable $($ Cronbach's alpha $=0.85)$ measure of affect (Watson et al., 1988).

\section{Results}

The means, standard deviations and reliability coefficients are contained in Table 1 . All of the variables achieved satisfactory reliability coefficients except the surface acting variable (0.56) and the deep acting variable (0.57) of the Emotional Labour Scale (Brotheridge and Lee, 2003). While the reliabilities achieved for these two scales were lower than in previous research (e.g., Brotheridge and Lee, 2003), we defer to Cortina (1993) who notes that reliability coefficients are susceptible to both variance and the number of items in the scale. As each of these scales contained three items we included them in our analysis in line with procedures established in previous published research (e.g., Judge et al., 1999). In retaining these scales in our analysis, we also note that this 
distinction was clear in observations made by the researchers of the respondents' behaviour. There was clear evidence (based on observation) that the respondents engaged in both deep acting (genuine shows of emotion to customers and other employees) and surface acting (following an emotional script). The ability of the respondents to distinguish between these constructs is evident from the correlations in Table 1.

Table 1 Means, standard deviations, correlations and inter-item reliabilities $(n=131)^{\mathrm{a}}$

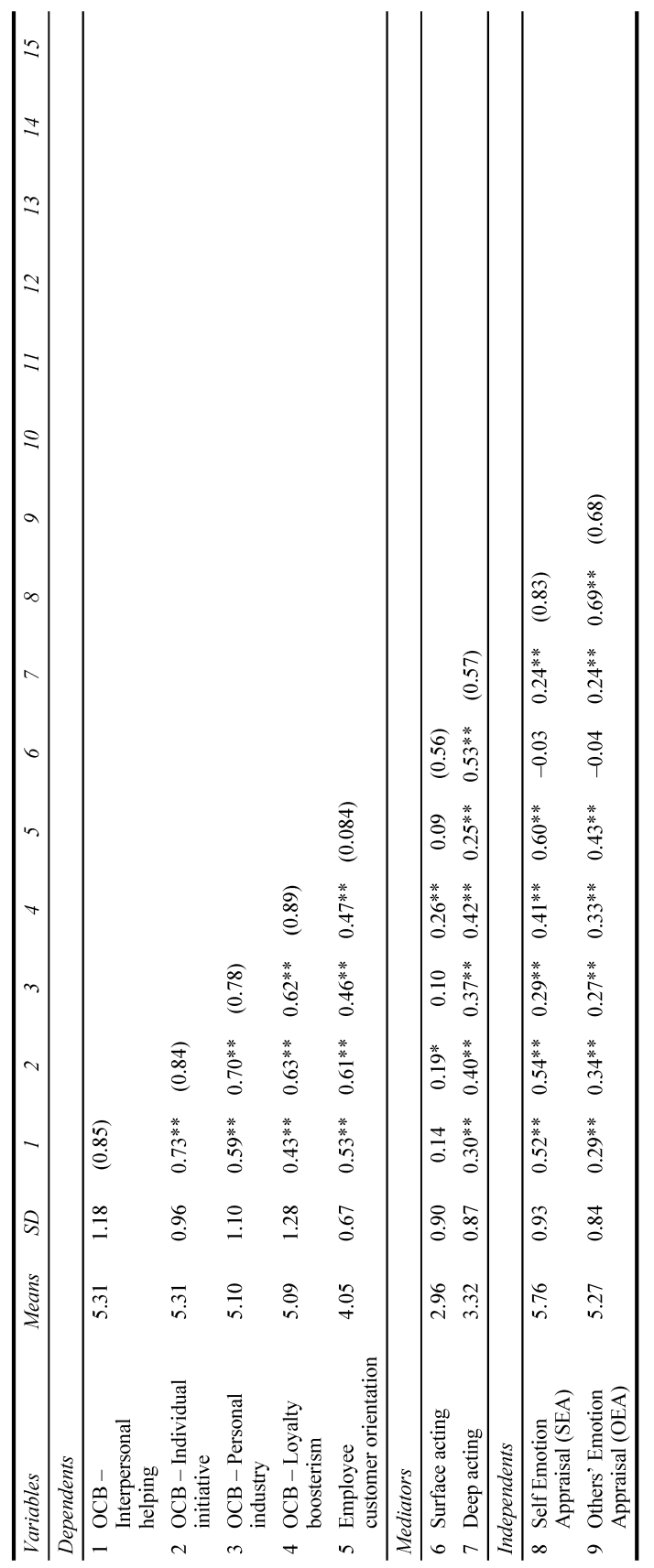


Table 1 Means, standard deviations, correlations and inter-item reliabilities $(n=131)^{\mathrm{a}}$ (continued)

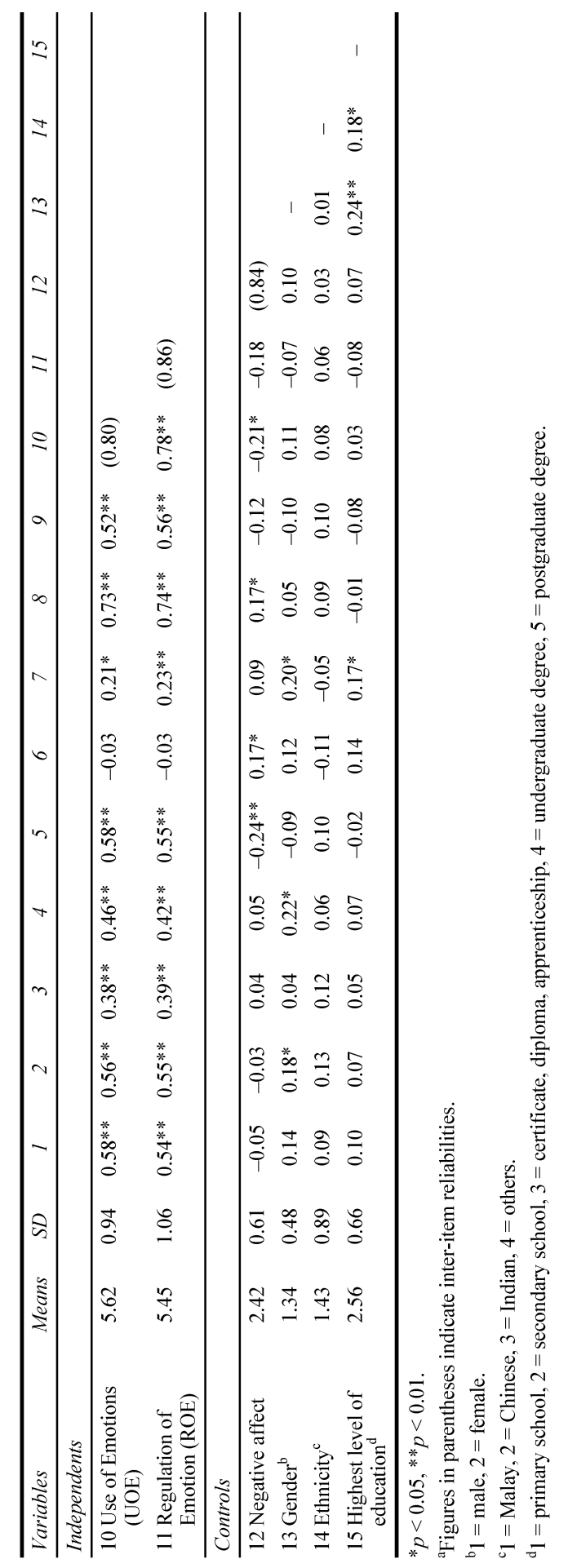


Table 1 shows all EI dimensions are significantly and positively correlated with all OCB dimensions. These data provide support for Hypothesis 1. An examination of the correlation table (Table 1) also shows that all EI dimensions were significantly and positively related to deep acting. Based on these data, Hypothesis 2, Hypothesis 3, Hypothesis 4 and Hypothesis 5 are supported. Significant positive results were also found between deep acting and all OCB dimensions. Hypothesis 6 is therefore supported. As expected, some of the control variables were significantly linked to EL and OCB (Table 1). Importantly, there were no significant correlations regarding ethnicity, which suggests this variable did not have an impact upon employees' displays of emotion and OCBs.

Taken together, these results suggest it is reasonable to test for mediation (see Baron and Kenny, 1986). Initially, the data reveals that EI is linked to OCB (Hypothesis 1). At the bivariate level, there is evidence that EI is related to the EL deep acting scale (Hypotheses 2-5) and that the EL deep acting scale is related to OCB (Hypothesis 6). Hypothesis 7 predicts that deep acting will mediate the relationship between EI abilities and OCB. To test this, a set of five hierarchical regression analyses were performed, where the dependent variables were each of the five dimensions of OCB. The control variables were entered in Step 1. The four EI dimensions were entered as independent variables in Step 2. Finally, the mediator, deep acting, and the second EL process, surface acting (acting here as a control variable) was entered in Step 3.

Table 2 examines the prediction that deep acting mediates the relationship between EI and three of the OCB dimensions: interpersonal helping, individual initiative and personal industry. No support was found for the mediated relationship in relation to interpersonal helping. Whilst all EI dimensions were significantly associated with deep acting (Table 1) and deep acting significantly influenced interpersonal helping in Tables 1 and 2 (Model 3; $\beta=0.30, p<0.01$ ), this later relationship was not found in the full model (Model 4). The combination of independent variables (after including the controls) was significant in Model 2 and accounted for $34 \%(p<0.001)$ of the unique variance of interpersonal helping. Model 2 revealed that employees' use of emotion $(\beta=0.32$, $p<0.01$; Model 2) directly influenced their levels of interpersonal helping.

Support was found for the mediated relationship involving individual initiative as the dependent variable (Table 2, Models 6-8). The combination of mediator variables significantly accounted for $6 \%(p<0.01)$ of the unique variance of individual initiative in Model 8. All EI dimensions were significantly associated with deep acting (Table 1) and deep acting significantly predicted individual initiative in Tables 1 and 2, Model 7 $(\beta=0.40, p<0.001)$ and Model $8(\beta=0.20, p<0.05)$. In Table 2 , regulation of emotion $(\beta=0.27, p<0.05$; Model 6$)$ also emerged as a predictor of individual initiative. The beta weight for regulation of emotion $(\beta=0.23$, n.s) reduced to non-significant levels in Model 8 which suggests the positive relationship between regulation of emotion and individual initiative was fully mediated by deep acting.

Support was found for the mediated relationship involving personal industry as the dependent variable (Table 2, Models 10-12). The combination of mediator variables significantly accounted for 7\% $(p<0.01)$ of the unique variance of personal industry in Model 12. All EI dimensions were significantly associated with deep acting (Table 1) and deep acting significantly predicted personal industry in Table 2 , Model $10(\beta=0.44$, $p<0.001)$ and Model $12(\beta=0.33, p<0.001)$. Regulation of emotion $(\beta=0.27$, $p<0.05$; Model 10) also emerged as a predictor of personal industry. The beta weight for 
regulation of emotion reduced to non-significant levels in Model $12(\beta=0.21$, n.s $)$ which suggests the positive relationship between regulation of emotion and individual initiative was fully mediated by deep acting.

Table 2 Regression results for determinants of organisational citizenship behaviour: interpersonal helping, individual initiative and personal industry

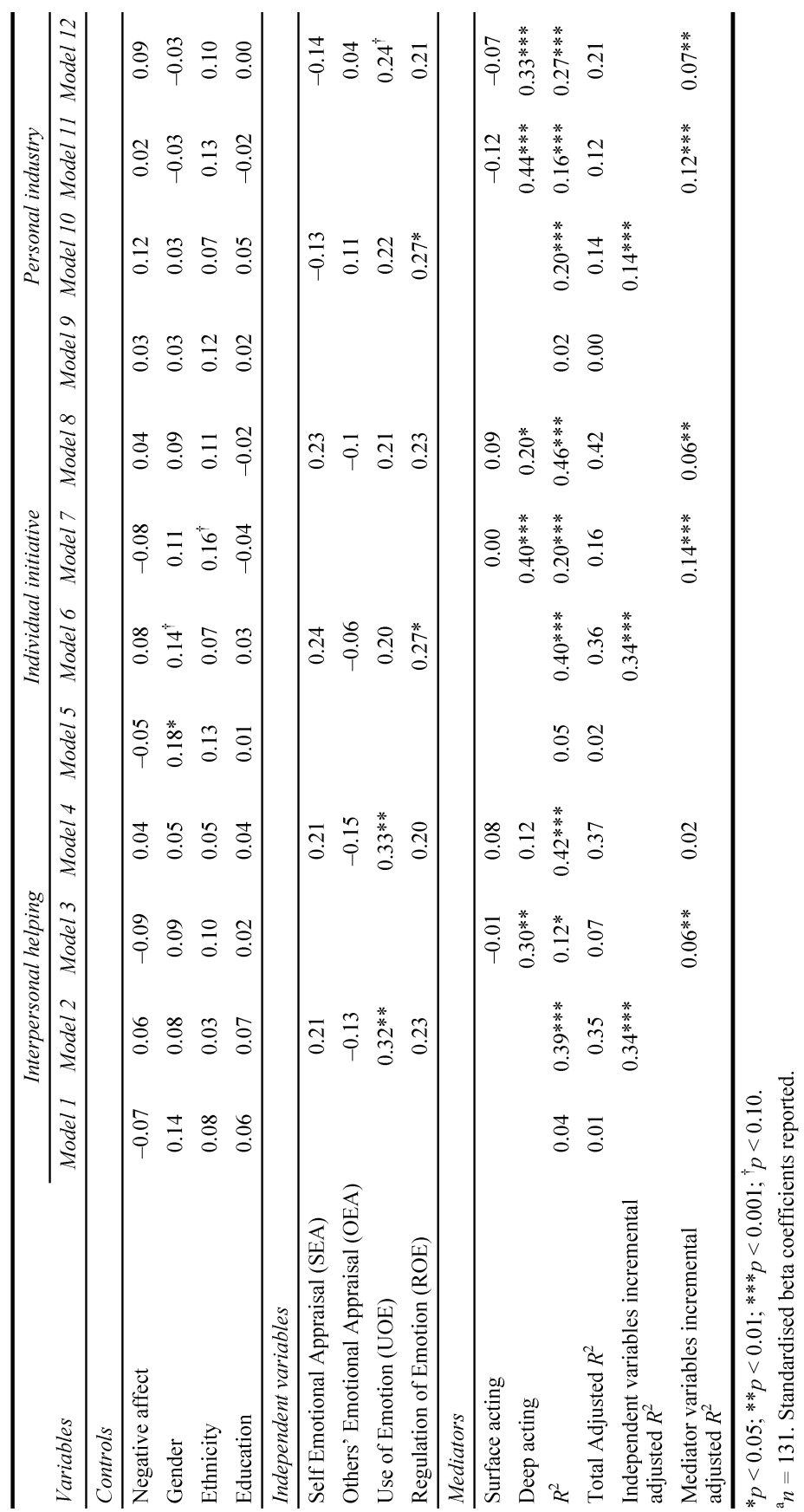


Table 3 Regression results for determinants of organisational citizenship behaviour: loyalty boosterism and customer orientation

\begin{tabular}{|c|c|c|c|c|c|c|c|c|}
\hline \multirow[b]{2}{*}{ Variables } & \multicolumn{4}{|c|}{ Loyalty boosterism } & \multicolumn{4}{|c|}{ Customer orientiation } \\
\hline & Model 1 & Model 2 & Model 3 & Model 4 & Model 5 & Model 6 & Model 7 & Model 8 \\
\hline \multicolumn{9}{|l|}{ Controls } \\
\hline Negative affect & 0.03 & 0.14 & -0.01 & 0.09 & $-0.24 * *$ & -0.10 & $-0.26^{* *}$ & -0.13 \\
\hline Gender & $0.22 *$ & $0.20 *$ & 0.15 & 0.15 & -0.06 & -0.12 & -0.11 & $-0.15^{*}$ \\
\hline Ethnicity & 0.05 & 0.00 & 0.09 & 0.04 & 0.11 & 0.04 & 0.13 & 0.07 \\
\hline Education & 0.01 & 0.03 & -0.05 & -0.02 & -0.01 & 0.01 & -0.05 & -0.02 \\
\hline \multicolumn{9}{|l|}{ Independent variables } \\
\hline $\begin{array}{l}\text { Self Emotional } \\
\text { Appraisal (SEA) }\end{array}$ & & 0.03 & & 0.03 & & $0.34 * *$ & & $0.34 * *$ \\
\hline $\begin{array}{l}\text { Others' Emotional } \\
\text { Appraisal (OEA) }\end{array}$ & & 0.12 & & 0.08 & & 0.00 & & -0.02 \\
\hline Use of Emotion (UOE) & & 0.25 & & $0.26^{*}$ & & $0.27 *$ & & $0.28 *$ \\
\hline $\begin{array}{l}\text { Regulation of Emotion } \\
\text { (ROE) }\end{array}$ & & 0.18 & & 0.13 & & 0.06 & & 0.03 \\
\hline \multicolumn{9}{|c|}{ Mediators } \\
\hline Surface acting & & & 0.07 & 0.15 & & & 0.00 & 0.10 \\
\hline Deep acting & & & $0.36^{* * *}$ & $0.20 *$ & & & $0.31 * *$ & 0.11 \\
\hline$R^{2}$ & 0.05 & $0.29 * * *$ & $0.20 * * *$ & $0.37 * * *$ & $0.07 *$ & $0.43 * * *$ & $0.16^{* * *}$ & $0.46 * * *$ \\
\hline Total adjusted $R^{2}$ & 0.02 & 0.25 & 0.17 & 0.32 & 0.04 & 0.39 & 0.12 & 0.41 \\
\hline $\begin{array}{l}\text { Independent variables } \\
\text { incremental adjusted } R^{2}\end{array}$ & & $0.23 * * *$ & & & & $0.35 * * *$ & & \\
\hline $\begin{array}{l}\text { Mediator variables } \\
\text { incremental adjusted } R^{2}\end{array}$ & & & $0.15 * * *$ & $0.08 * * *$ & & & $0.08 * *$ & $0.02 *$ \\
\hline
\end{tabular}

$* p<0.05 ; * * p<0.01 ; * * * p<0.001$.

${ }^{\mathrm{a}} n=131$. Standardised beta coefficients reported.

Table 3 examines the prediction that deep acting mediates the relationship between EI and the two remaining OCB dimensions: loyalty boosterism and employee customer orientation. No support was found for the mediated relationship regarding loyalty boosterism (Table 3, Models 2-4). In Model 4, the combination of mediator variables significantly accounted for $8 \%(p<0.001)$ of the unique variance of loyalty boosterism. All EI dimensions were significantly associated with deep acting (Table 1) and deep acting positively predicted loyalty boosterism in Table 2 , Model $3(\beta=0.36, p<0.001)$ and Model $4(\beta=0.20, p<0.05)$. However, whilst the use of emotion significantly influenced levels of loyalty boosterism in Model $4(\beta=0.26, p<0.01)$, it did not in Model $2(\beta=0.25$, n.s). Thus use of emotion and deep acting both directly and positively influence employees' loyalty boosterism.

No support was found for the mediated relationship regarding employee customer orientation (Table 3, Models 6-8). In Model 8, the combination of mediator variables significantly accounted for $2 \%(p<0.05)$ of the unique variance of employee customer orientation. Whilst deep acting significantly predicted employee customer orientation 
in Table 3, Model $7(\beta=0.31, p<0.01)$, it did not in Table $8(\beta=0.11$, n.s $)$. Self emotional appraisal and use of emotion, however, did emerge as having a significant direct influence on employees' customer orientation levels in Model $6(\beta=0.34$, $p<0.01 ; \beta=0.27, p<0.05$, respectively) and Model $8(\beta=0.34, p<0.01 ; \beta=0.28$, $p<0.05$, respectively).

\section{Discussion}

Figure 1 presented a conceptual framework that linked EI, EL and OCB and proposed the mediating role of the EL process of deep acting in the relationship between EI and OCB. Overall, our results partially supported these relationships and showed that deep acting mediated the relationship between regulation of emotion and two indicators of OCB: individual initiative and personal industry (Hypothesis 7). The other major contribution of this study is the use of a Malaysian service worker sample. To the best of our knowledge, minimal data has been collected in Malaysia, despite researchers calling for the investigation of emotion constructs in non-Western settings (e.g., Côté and Miners, 2006; Grandey et al., 2005). The service sector is a significant component of the Malaysian economy, so there is clear value in identifying what predicts better service performance from Malaysian employees.

Hypothesis 1, which predicted a positive relationship between EI and OCB, was supported. Abraham (2003) argues emotionally intelligent employees are more receptive to the emotions of others and are also more willing to volunteer and expend extra effort to achieve organisational goals. Furthermore, in Malaysian business contexts, the social and relational aspect of interactions take precedence as a result of cultural norms (Storz, 1999). Clearly there is a link between emotional skills and positive OCBs, but the strong predictor of this relationship was the ability to use emotions. On this basis, the ability to generate appropriate emotions within a work context is an important skill in promoting OCBs. For instance, an employee who is able to generate enthusiasm is more likely to promote higher levels of OCBs.

Our results supported Hypotheses 2-5 which predicted a link between EI and deep acting. Clearly, deep acting requires emotional awareness and management skills to be operationalised (Grandey et al., 2005). By contrast, no link was found between surface acting and EI. We did not develop any hypotheses around surface acting, as we expected no result. While conclusions cannot be drawn from a null hypothesis, if the data are considered together, these results suggest a difference between the skills needed to engage in deep vs. surface acting. Surface acting is associated with explicitly following organisational display rules (Diefendorff et al., 2006) and therefore it could be argued that they do not require EI abilities. For example, always smiling at customers was a display rule from our sample organisation that staff had to follow. Being an organisationally prescribed rule, it is feasible that most employees would have the skills to give customers fake smiles (surface acting) whether they are emotionally intelligent or not. On the other hand, deep acting (or generating genuine emotion) requires emotional skills. As a link has been shown between genuine displays of emotion and better customer service (Ashforth and Humphrey, 1993), ensuring that employees in service roles have these skills is important. 
Hypothesis 6, which predicted a link between deep acting and OCB, was supported. This is consistent with other researchers who suggest employees who used deep acting in their everyday dealings with customers are more likely to engage in extra-role behaviours as they display genuine emotions enabling them to empathise with their customers (Johnson and Indvik, 1999). We note that emotions that are generated to create a good customer service interaction will also have an impact on other employees through emotional contagion (Kelly and Barsade, 2001). For this contagion to occur however the emotions displayed have to be genuine.

Hypothesis 7 predicted that deep acting mediates the effect of EI on OCB. Partial support was found for this in terms of the mediating role of deep acting on the Regulation of Emotion and Individual Initiative relationship, and the Regulation of Emotion and Personal Industry relationship. Individual initiative and personal industry are intra personal aspects of OCB. These are enacted by individuals without reference to others. Our findings that deep acting is the mechanism through which regulation of emotions impacts on two intra personal aspects of OCB suggests that employees really need to feel emotions (deep acting) to engage in these positive behaviours. On the other hand, interpersonal helping and employee customer orientation are focused on attending to the needs of others (Albrecht and Zemke, 1985). Similarly, loyalty boosterism is focused on the needs of the organisation and again we found no role for deep acting. To undertake these tasks employees do not need to really feel emotion, they only need to see this type of behaviour as an organisational norm and work within the rules of the organisation. Based on observations made by one of the researchers during data collection, prima facie evidence of a distinction between deep acting and surface acting was observed. This evidence is based on research that shows a clear distinction between genuine displays of emotion (deep acting) and faked displays of emotion (surface acting) (Morris and Feldman, 1996).

Finally, we consider the impact of our findings in a non-Western setting. A large amount of criticism of the EI construct is the Western centred focus (Fisher and Ashkanasy, 2000). The abilities involved in EI have been portrayed as meeting a specific set of cultural norms (Grandey et al., 2005). Our study was comprised of a sample that was non-Western in composition. Although there has been extensive research into national culture being a determinant of behaviour (e.g., House et al., 2004) and criticisms over studies that do not take account of national culture (Mayer et al., 2000), the results from our study reflected the findings you would expect in a Western setting. We noted that the location of our study was a 5-star hotel chain in Malaysia, which is often used by Western tourists. The display rules promoted in this organisation mirror Western service providers whose focus is on a pleasant interaction. This highlights the importance of context within the culture that is being examined. From our findings we infer that many Western values of customer service were applied in this setting. Perhaps it is not surprising, then, that our results mirrored the relationships one would expect from a Western sample.

\subsection{Limitations and future research directions}

There are some limitations in our study. Fore most, the cross-sectional design of the study suggests that common method variance may be an issue. While we wanted to separate dependant and independent variables to add efficacy to our results, the nature of the research in an applied setting required that all the data be collected at one time. 
To partly address common method variance, we adopted a varying response format with different anchors for each scale, and controlled for the influence of negative affect in our regression analyses.

Data were collected in Malaysia where English is a second language. We acknowledge English literacy might have been an issue regarding survey responses. Surveys were not translated into Malay for several reasons. First, if translated literally, some words could be misunderstood. Second, in some instances, there were no words in Malay to describe slight distinctions between words in English. For example, scared and afraid in the PANAS both translate into the same word in Malay. However, the participants were required as a part of their job to have a conversational level of English. The researchers were also available to assist if there were problems with understanding the survey. The pilot study that was conducted to test the clarity and accuracy of the questions being asked encountered no difficulty with question understanding. We do note, however, that the less than satisfactory reliability coefficients found for the EL scales may reflect misunderstanding of some fine distinctions in the wording of the survey. We retained these scales in our analysis as the correlation in Table 1 suggests discriminant validity as respondents were able to distinguish between these constructs.

The final limitation in the study was the possibility of respondent bias through social desirability. To address this concern, the participants were advised that their responses were to remain anonymous and that individual respondent's responses would not be revealed to the management of the hotel chain.

\subsection{Implications}

Managers need to recognise the importance of EI, EL and OCB in improving employee performance in service organisations. In particular, it is vital for managers in service areas to realise how EI contributes to the EL process of deep acting, which in turn will result in specific types of OCB (individual initiative and personal industry). The clear links between deep acting and improved customer perceptions (e.g., Brotheridge and Grandey, 2002), and between OCB and improved workplace performance (Donovan et al., 2004) and a more pleasant working environment (Neuman and Kickul, 1998), mean that these are important behaviours to encourage in service settings. Our research highlights that this occurs in a broad range of settings across cultures and not just in Western service settings.

On this basis, managers should promote the importance of EI, EL and OCB to their employees, with a particular emphasis on the importance of deep acting. This could be done by managers encouraging a positive affective climate that produces appropriate deep acting (Grandey, 2003). Research that deals with emotional contagion suggests that exposure to a specific emotional climate will result in those being exposed adopting those emotions (Pugh, 2001). Through this study, it is hoped that managers will be encouraged to identify suitable training needs for their employees in these are as. While the debate over ability EI and trait EI has implications for whether EI can be trained (see Lindebaum, 2009), there are specific training possibilities that could be explored. More specific training in identifying the emotions of customers, reading body language and dealing with the emotional aspect of difficult customers could be implemented (Caruso and Salovey, 2004). By having trained and skilled front-line employees, who are proficient in EI, deep acting and OCB, service organisations will 
create a better service environment (improved individual initiative and personal industry), which in turn will increase customer satisfaction. Increased customer satisfaction will improve an organisation's performance in the long run and will create a competitive advantage.

\section{References}

Abraham, C. (2003) 'The relationship between emotional intelligence and work attitudes behaviour and outcomes - an examination among senior managers', Journal of Managerial Psychology, Vol. 18, Nos. 7-8, pp.788-813.

Albrecht, K. and Zemke, R. (1985) Service America! Doing Business in the New Economy, Dow Jones-Irwin, Homewood, IL.

Ashforth, B.E. and Humphrey, R.H. (1993) 'Emotional labor in service roles: the influence of identity', Academy of Management Review, Vol. 18, No. 1, pp.88-115.

Bar-On, R., Handley, R. and Fund, S. (2006) 'The impact of emotional intelligence on performance', in Druskat, V.U., Sala, F. and Mount, G. (Eds.): Linking Emotional Intelligence And Performance at Work: Current Research Evidence with Individuals and Groups, Lawrence Erlbaum, Mahwah, NJ, pp.3-19.

Baron, R.M. and Kenny, D.A. (1986) 'The moderator-mediator variable distinction in social psychological research: conceptual, strategic, and statistical considerations', Journal of Personality and Social Psychology, Vol. 51, No. 6, pp.1173-1182.

Becker, T.E. and Keman, M.C. (2003) 'Matching commitment to supervisors and organizations to in-role and extra-role performance', Human Performance, Vol. 16, pp.327-348.

Brotheridge, C.M. and Grandey, A.A. (2002) 'Emotional labour and burnout: comparing two perspectives of 'people work', Journal of Vocational Behaviour, Vol. 60, pp.17-39.

Brotheridge, C.M. and Lee, R.T. (2003) 'Development and validation of the Emotional Labour Scale', Journal of Occupational and Organizational Psychology, Vol. 76, pp.365-379.

Caruso, D.R. and Salovey, P. (2004) The Emotionally Intelligent Manager: How to Develop and Use the Four Key Emotional Skills of Leadership, Jossey Bass, San Francisco, CA.

Castro, C.B., Armario, E.M. and Ruiz, D.M. (2004) 'The influence of employee organizational citizenship behaviour on customer loyalty', International Journal of Service Industry Management, Vol. 15, No. 1, pp.27-53.

Cherniss, C. (2010) 'Emotional intelligence: towards clarification of a concept', Industrial and Organizational Psychology: Perspectives on Science and Practice, Vol. 3, pp.110-126.

Cortina, J.M. (1993) 'What is coefficient alpha? An examination of theory and applications', Journal of Applied Psychology, Vol. 78, pp.98-104.

Côté, S. and Miners, C.T.H. (2006) 'Emotional intelligence, cognitive intelligence, and job performance', Administrative Science Quarterly, Vol. 51, pp.1-28.

Daus, C.S. and Ashkanasy, N.M. (2005) 'The case for the ability-based model of emotional intelligence in organizational behaviour', Journal of Organizational Behaviour, Vol. 26, pp. $453-466$.

Diefendorff, J.M. and Richard, E.M. (2003) 'Antecedents and consequences of emotional display rule perceptions', Journal of Applied Psychology, Vol. 88, No. 2, pp.284-294.

Diefendorff, J.M., Richard, E.M. and Croyle, M.H. (2006) 'Are emotional display rules formal job requirements? Examination of employee and supervisor perceptions', Journal of Occupational and Organizational Psychology, Vol. 79, pp.273-298.

Donovan, D.T., Brown, T.J. and Mowen, J.C. (2004) 'Internal benefits of service-worker customer orientation: job satisfaction, commitment, and organizational citizenship behaviours', Journal of Marketing, Vol. 68, pp.128-146. 
Ekman, P. and Friesen, W.V. (1971) 'Constants across cultures in the face and emotion', Journal of Personality and Social Psychology, Vol. 17, pp.24-29.

Fisher, C.D. and Ashkanasy, N.M. (2000) 'The emerging role of emotions in work life: an introduction', Journal of Organizational Behaviour, Vol. 21, pp.123-129.

Frese, M. and Fay, D. (2001) 'Personal initiative: an active performance concept for work in the 21st century', Research in Organizational Behaviour, Vol. 23, pp.133-187.

Galli, C. and Zammuner, V.L. (2005) 'Wellbeing: causes and consequences of emotion regulation in work settings', International Review of Psychiatry, Vol. 17, No. 5, pp.355-364.

Giardini, A. and Frese, M. (2006) 'Reducing the negative effects of emotion work in service occupations: emotional competence as a psychological resource', Journal of Occupational Health Psychology, Vol. 11, No. 1, pp.63-75.

Goleman, D. (1998) Working with Emotional Intelligence, Bantam Books, New York, NY.

Gosserand, R.H. and Diefendorff, J.M. (2005) 'Emotional display rules and emotional labour: the moderating role of commitment', Journal of Applied Psychology, Vol. 90, No. 6, pp.1256-1264.

Grandey, A.A. (2003) 'When "the show must go on": surface and deep acting as determinants of emotional exhaustion and peer-rated service delivery', Academy of Management Journal, Vol. 46, No. 1, pp.86-96.

Grandey, A.A., Fisk, G.M. and Steiner, D.D. (2005) 'Must "service with a smile" be stressful? The moderating role of personal control for American and French employees', Journal of Applied Psychology, Vol. 90, No. 5, pp.893-904.

Hallett, T. (2003) 'Emotional feedback and amplification in social interaction', The Sociological Quarterly, Vol. 44, No. 4, pp.705-726.

Han, Y. and Altman, Y. (2010) 'Confucian moral roots of citizenship behaviour in China', Asia-Pacific Journal of Business Administration, Vol. 2, No. 1, pp.35-52.

Härtel, C.E.J., Gough, H. and Härtel, G.F. (2008) 'Work-group emotional climate, emotion management skills, and service attitudes and performance', Asia Pacific Journal of Human Resources, Vol. 46, pp.21-37.

Hennig-Thurau, T., Groth, M., Paul, M. and Gremler, D.D. (2006) 'Are all smiles created equal? How emotional contagion and emotional labor affect service relationships', Journal of Marketing, Vol. 70, pp.58-73.

Hochschild, A.R. (1983) The Managed Heart: Commercialization of Human Feeling, University of California Press, Berkeley.

House, R.J., Hanges, P.J., Javidan, M., Dorfman, P. and Gupta,V. (2004) Culture, Leadership and Organizations: The GLOBE Study of 62 Societies, Sage Thousand Oaks, CA.

Johnson, J.W. (1996) 'Linking employee perceptions of service climate to customer satisfaction', Personnel Psychology, Vol. 49, No. 4, pp.831-851.

Johnson, P.R. and Indvik, J. (1999) 'Organizational benefits of having emotionally intelligent managers and employees', Journal of Workplace Learning, Vol. 11, No. 3, pp.84-88.

Jordan, P.J., Dasborough, M.T., Daus, C.S. and Ashkanasy, N.M. (2010) 'A call to context: comments on emotional intelligence and emotional social competencies', Industrial and Organizational Psychology: Perspectives on Science and Practice, Vol. 3, pp.145-148.

Judge, T.A., Thoresen, C.J., Pucik, V. and Welbourne, T. (1999) 'Managerial coping with organizational change: a dispositional perspective', Journal of Applied Psychology, Vol. 84, No. 1, pp.107-122.

Kelly, J.R. and Barsade, S.G. (2001) 'Mood and emotions in small groups and work teams', Organizational Behaviour and Human Decision Processes, Vol. 86, pp.99-130.

Lam, S.S.K., Chun, H. and Law, K.S. (1999) 'Organizational citizenship behaviour: comparing perspectives of supervisors and subordinates across four international samples', Journal of Applied Psychology, Vol. 84, No. 4, pp.594-623. 
Leidner, R. (1999) 'Emotional labor in service work', The Annals of the American Academy, Vol. 561, pp.81-95.

Lindebaum, D. (2009) 'Rhetoric or remedy? A critique on developing emotional intelligence', Academy of Management Learning \& Education, Vol. 8, pp.225-237.

Lopes, P.N., Salovey, P., Côté, S. and Beers, M. (2005) 'Emotion regulation abilities and the quality of social interaction', Emotion, Vol. 5, No. 1, pp.113-118.

Matsumoto, D. (1990) 'Cultural similarities and differences in display rules', Motivation and Emotion, Vol. 14, pp.195-214.

Mayer, J.D. and Salovey, P. (1997) 'What is emotional intelligence?', in Salovey, P. and Sluyter, D.J. (Eds.): Emotional Development and Emotional Intelligence: Educational Implications, Basic Books, New York, pp.3-31.

Mayer, J.D., Caruso, D.R. and Salovey, P. (2000) 'Emotional intelligence meets traditional standards for an intelligence', Intelligence, Vol. 27, No. 4, pp.267-298.

Meier, K.J., Mastracci, S.H. and Wilson, K. (2006) 'Gender and emotional labor in public organizations: an empirical examination of the link to performance', Public Administration Review, Vol. 66, No. 6, pp.899-909.

Messer, B.A.E. and White, F.A. (2006) 'Employees' mood, perceptions of fairness and organizational citizenship behaviour', Journal of Business and Psychology, Vol. 21, No. 1, pp.65-82.

Mikolajczak, M., Menil, C. and Luminet, O. (2007) 'Explaining the protective effect of trait emotional intelligence regarding occupational stress: exploration of challenge/threat appraisals and emotional labour processes', Journal of Research in Personality, Vol. 41, pp.1107-1117.

Moorman, R.H. and Blakely, G.L. (1995) 'Individualism-collectivism as an individual difference predictor of organizational citizenship behaviour', Journal of Organizational Behaviour, Vol. 16, No. 2, pp.127-142.

Morris, J.A., and Feldman, D.C. (1996) 'The dimensions, antecedents and consequences of emotional labor', Academy of Management Review, Vol. 21, pp.986-1010.

Neuman, G.A. and Kickul, J.R. (1998) 'Organizational citizenship behaviours: achievement orientation and personality', Journal of Business and Psychology, Vol. 13, No. 2, pp.263-279.

Organ, D.W. (1988) Organizational Citizenship Behaviours: The Good Soldier Syndrome, Lexington Books, Lexington, MA.

Petrides, K.V., Pérez-González J.C. and Furnham, A. (2007) 'On the criterion and incremental validity of trait emotional intelligence', Cognition \& Emotion, Vol. 21, No. 1, pp.26-55.

Poon, J.M.L. (2004) 'Career commitment and career success: moderating role of emotion perception', Career Development International, Vol. 9, pp.374-390.

Pugh, S.D. (2001) 'Service with a smile: emotional contagion in the service encounter', Academy of Management Journal, Vol. 44, pp.1018-1027.

Rupp, D.E. and Spencer, S. (2006) 'When customers lash out: the effect of customer interactional injustice on emotional labour and the mediating role of discrete emotions', Journal of Applied Psychology, Vol. 91, No. 4, pp.971-978.

Salovey, P. and Grewal, D. (2005) 'The science of emotional intelligence', Current Directions in Psychological Science, Vol. 14, No. 6, pp.281-285.

Shipper, F., Kincaid, J., Rotondo, D.M. and Hoffman, R.C. (2003) 'A cross-culture exploratory study of the linkage between emotional intelligence and managerial effectiveness', International Journal of Organizational Analysis, Vol. 11, No. 3, pp.171-192.

Storz, M.L. (1999) 'Malay and Chinese values underlying the Malaysian business culture', International Journal of Intercultural Relations, Vol. 23, No. 1, pp.117-131.

Totterdell, P. and Holmann, D. (2003) 'Emotion regulation in customer service roles: testing a model of emotional labor', Journal of Occupational Health Psychology, Vol. 8, No. 1, pp.55-73. 
Tourism Malaysia Media Centre (2007) Retrieved 15th October 2007 from http://www. tourismmalaysia.gov.my/tourismbiz/media_centre/statistic.asp

Tsai, W.C. and Huang, Y.M. (2002) 'Mechanisms linking employee affective delivery and customer behavioural intentions', Journal of Applied Psychology, Vol. 87, No. 5, pp.1001-1008.

Watson, D., Clark, L.A. and Tellegen, A. (1988) 'Development and validation of brief measures of positive and negative affect: the PANAS scales', Journal of Personality and Social Psychology, Vol. 54, pp.1063-1070.

Wharton, A.S. (1993) 'The affective consequences of service work', Work and Occupation, Vol. 20, pp.205-232.

Wong, C.S. and Law, K.S. (2002) 'The effects of leader and follower emotional intelligence on performance and attitude: an exploratory study', The Leadership Quarterly, Vol. 13, pp.243-274.

Yoon, M.H. and Suh, J. (2003) 'Organizational citizenship behaviours and service quality as external effectiveness of contact employees', Journal of Business Research, Vol. 56, pp.597-611. 